\title{
CdTe Quantum Dot Fluorescence Modulation by Spin Crossover
}

\author{
Olena Kraieva ${ }^{1,+}$, Iurii Suleimanov ${ }^{1,2,+}$, Gábor Molnár ${ }^{1,+}$, Lionel Salmon ${ }^{1, *}$ and \\ Azzedine Bousseksou 1,* \\ 1 Laboratoire de Chimie de Coordination, CNRS 205 Route de Narbonne, Toulouse 31077, France; \\ olena.kraieva@lcc-toulouse.fr (O.K.); Iurii.suleimanov@lcc-toulouse.fr (I.S.); \\ gabor.molnar@lcc-toulouse.fr (G.M.) \\ 2 Department of Chemistry, National Taras Shevchenko University, 62a Volodymyrska street, \\ Kyiv 01601, Ukraine \\ * Correspondence: lionel.salmon@lcc-toulouse.fr (L.S.); Azzedine.bousseksou@lcc-toulouse.fr (A.B.); \\ Tel.: +33-05-61-33-31-78 (L.S. \& A.B.); Fax: +33-05-61-55-30-03 (L.S. \& A.B.) \\ + These authors contributed equally to this work.
}

Academic Editors: Guillem Aromí and José Antonio Real

Received: 10 November 2015; Accepted: 4 February 2016; Published: 25 February 2016

\begin{abstract}
Nanocomposite materials containing Cadmium Telluride (CdTe) nanocrystals and $\left[\mathrm{Fe}(\mathrm{H}-\mathrm{trz})_{2}(\operatorname{trz})\right] \mathrm{BF}_{4}$ nanoparticles were synthesized and investigated for the coupling between their photoluminescent and spin crossover properties. The bright CdTe emission around $550 \mathrm{~nm}$ was found to decrease reversibly when switching the ferrous complex from the high spin (HS) to the low spin (LS) state, which was attributed to the spectral overlap of the luminescence with the absorption of the complex in the latter electronic configuration. A significant irreversible change of the luminescence signal (photobleaching) was also observed both in emission intensity and lifetime measurements.
\end{abstract}

Keywords: nanocomposite; quantum dots; luminescence; spin crossover

\section{Introduction}

Recently, a series of hybrid or nanocomposite materials combining fluorescent and spin crossover (SCO) properties have been described in the literature [1-28]. The main appeal of these hybrid materials is related to the fact that-for an appropriate combination of the two constituents- the fluorescence intensity can be a sensitive probe of the spin-state of the system. There is also a fundamental interest in studying energy transfer mechanisms between fluorophores and transition metal complexes in their different spin states. In most cases, the luminescence intensity variation in response to the spin state switching was attributed to an efficient spectral overlap between the fluorophore emission and the absorption of the SCO complex in a given spin state, leading to enhanced excited state energy transfer from the luminophore to the complex in that spin state, i.e., to a decrease of the luminescence intensity. Depending on the spatial proximity of the luminescent and SCO centers, this energy transfer can be either radiative or resonant, but such mechanistic aspects have been scarcely investigated [2]. In a few cases, other mechanisms of luminescence modulation by SCO, related to structural instead of electronic changes, have been also proposed [14,22].

The vast majority of the reported hybrid fluorescent SCO systems are based on organic fluorophores. However, a serious drawback of organic dyes is their rather strong photobleaching. To overcome this problem we have recently elaborated $\left[\mathrm{Fe}(\mathrm{H} \text {-trz })_{2}(\operatorname{trz})\right] \mathrm{BF}_{4} @ \mathrm{SiO}_{2}$ core-shell nanoparticles (H-trz $=1,2,4$-triazole and $\operatorname{trz}=1,2,4$-triazolato), which we surface grafted with a 
rare-earth $\left(\mathrm{Tb}^{3+}\right)$ containing fluorophore [24]. This lanthanide-SCO nanocomposite demonstrated high luminescence stability, i.e., a well reproducible modulation of the luminescence intensity by the spin-state switching. In this context, semiconductor nanocrystals ("quantum dots") are a priori also very interesting candidates because of their bright luminescence $[29,30]$. In addition, they exhibit a short luminescence lifetime and are usually more stable than organic dyes. The electrons in quantum dots are confined in a small space and typically when the radii of the nanocrystal is smaller than the exciton Bohr radius, the luminescence emission wavelength becomes size dependent. This property has been exploited in different applications and it is also obviously very advantageous in the context of hybrid luminescent SCO materials as one can easily "size tune" the energy levels of the luminophore in order to reach an appropriate spectral overlap with the absorption of the SCO complex. Based on these ideas, in this paper we describe nanocomposite materials, consisting of CdTe nanocrystals and $\left[\mathrm{Fe}(\mathrm{H}-\mathrm{trz})_{2}(\operatorname{trz})\right] \mathrm{BF}_{4} \mathrm{SCO}$ particles, which display a coupling between the two electronic phenomena.

\section{Results and Discussion}

The luminescence emission spectrum of the CdTe nanocrystals in solid state is shown in Figure 1a for selected temperatures between $298 \mathrm{~K}$ and $363 \mathrm{~K}$. Before the measurements, the sample was annealed at $400 \mathrm{~K}$ to remove traces of solvents. At room temperature, the emission peak is centered at $555 \mathrm{~nm}$ and the peak width at half-maximum is $c a .40 \mathrm{~nm}$. We observed this irreversible redshift and broadening of the emission (with respect to the as-received nanocrystals) systematically after the first heating of the sample. As it can be expected on heating, the luminescence peak exhibits a marked decrease of peak amplitude, an increase of the peak width and a small redshift. These changes were found only partially reversible (vide infra). Figure $1 \mathrm{~b}$ shows the absorption (diffuse reflectance) spectra of the iron complex in the two spin states. While the compound is basically colorless in the HS $\left({ }^{5} \mathrm{~T}\right)$ state, its color turns pink-violet in the LS $\left({ }^{1} \mathrm{~A}\right)$ state due to the emergence of a broad absorption peak centered around $540 \mathrm{~nm}$. Obviously, the spectral overlap between this metal-centered absorption and the CdTe emission is complete and one can thus expect a luminescence intensity decrease in the composites $\mathbf{1}$ and $\mathbf{2}$ when switching the complex from the HS to the LS state.
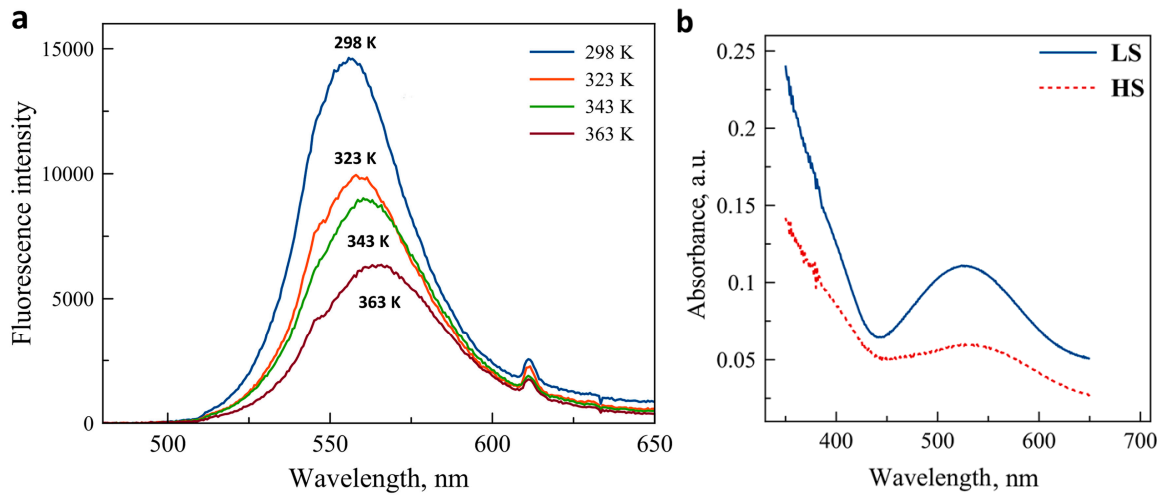

Figure 1. (a) Photoluminescence emission spectra of CdTe nanocrystals at a few selected temperatures (excitation at $450 \mathrm{~nm}$ ). (b) Absorption spectra of the SCO complex in the HS and LS states (reproduced by permission of The Royal Society of Chemistry).

TEM images of 1 revealed rod-like nanoparticles with an average width of ca. $45 \mathrm{~nm}$ and a length of ca. $90 \mathrm{~nm}$ (Figure 2a) in agreement with the size and morphology already reported for similar syntheses [31]. For sample 2, smaller, nearly spherical and strongly aggregated nanoparticles with an average diameter of $40 \mathrm{~nm}$ were revealed by the TEM analysis (Figure 2b). HRTEM images and EDX analyses of the two samples indicate that the quantum dots are randomly distributed on the surface of the SCO nanoparticles in an amount of $c a .1 \%-2 \% \mathrm{CdTe} / \mathrm{Fe}$ (see Figure $2 \mathrm{a}$ and the Supplementary Materials Figures S1-S3). 

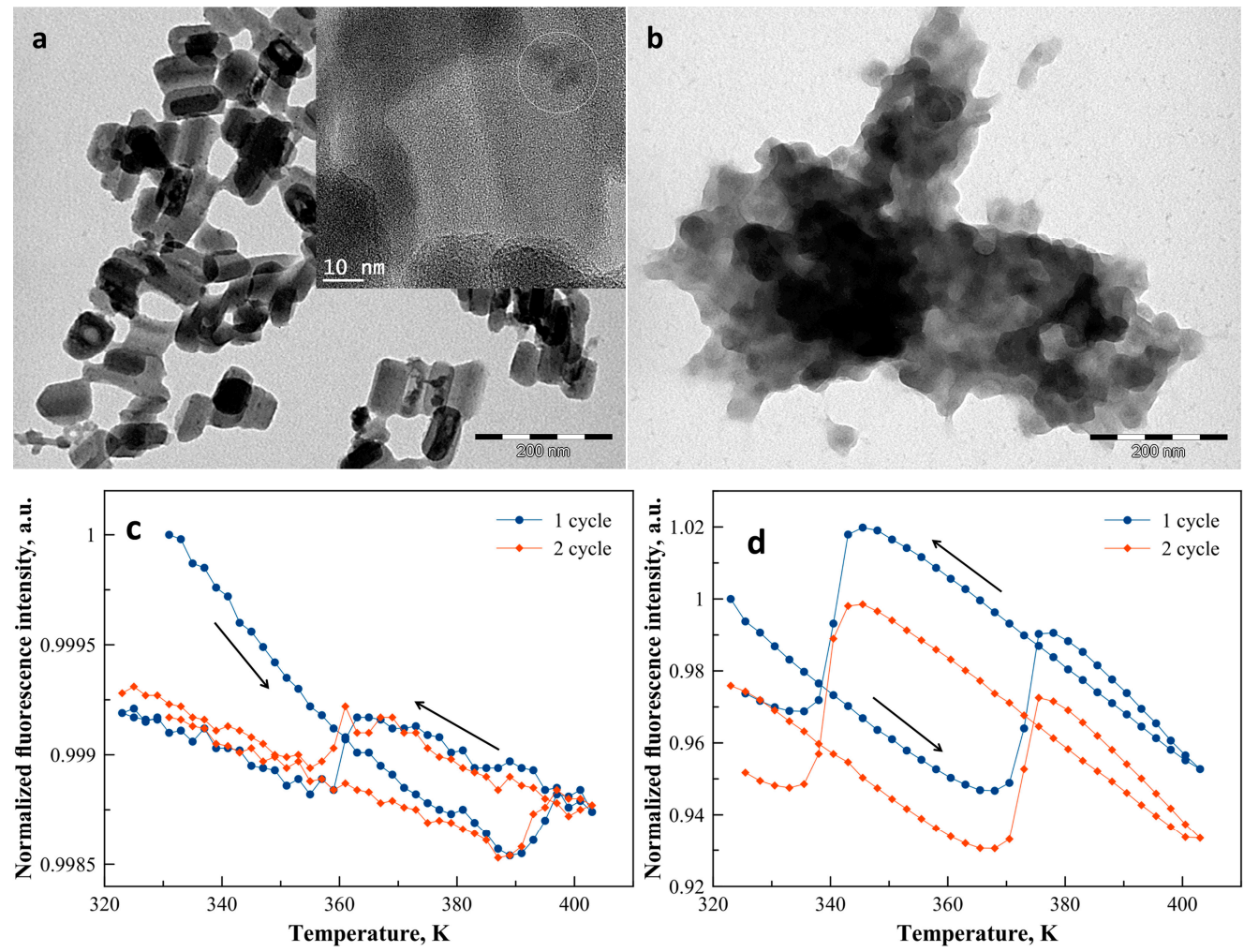

Figure 2. TEM images of samples 1 (a) and 2 (b). The HRTEM image of sample 1 in inset of (a) shows

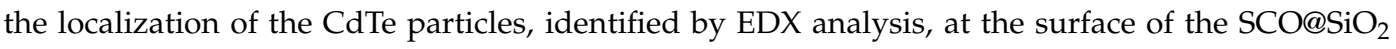
nanoparticles. Normalized luminescence intensity of samples 1 (c) and 2 (d) recorded at $550 \mathrm{~nm}$ (excitation at $450 \mathrm{~nm}$ ) as a function of the temperature for two successive thermal cycles (arrows indicate cooling and heating for the first cycle).

Figure 2 shows also the normalized fluorescence intensity of the composites recorded at $550 \mathrm{~nm}$ as a function of the temperature over two complete heating-cooling cycles between $323 \mathrm{~K}$ and $403 \mathrm{~K}$. For both nanocomposite samples, upon heating, the luminescence exhibits a linear decrease, which corresponds to the usual thermal quenching phenomenon due to the thermal activation of non-radiative decay channels. In addition, for both samples the thermal hysteresis associated with the spin transition is clearly discernible in the temperature dependence of the luminescence intensity. For sample 1, the LS to HS spin transition around $393 \mathrm{~K}$ leads to an abrupt increase of the luminescence intensity by only $0.03 \%$ (Figure $2 \mathrm{c}$ ). In the cooling mode, the inverse process occurs, i.e., a linear increase of the luminescence intensity down to ca. $362 \mathrm{~K}$ followed by an abrupt drop, which corresponds to the HS to LS transition. The wide ( $c a .35 \mathrm{~K}$ ) thermal hysteresis associated with the spin transition is a well-known feature of the complex and corresponds to the magnetic measurements reported previously for the non-fluorescent nanoparticles [31]. At the end of the first thermal cycle, one can observe nearly $1 \%$ irreversible decrease of the luminescence intensity, which we attribute to a photobleaching process. Similar behavior was observed for sample 2, but, in this case, not only the first, but also the second thermal cycle, involves a $c a .2 \%$ irreversible decrease of the luminescence intensity (Figure 2d). Moreover, the LS to HS (HS to LS) spin transition is detected at $373 \mathrm{~K}(345 \mathrm{~K})$ with a luminescence intensity change of $c a .5 \%$. In comparison with sample 1 , the observed shift of the hysteresis loop towards lower temperatures is probably related to the specific matrix effect of the BPEI shell [32]. On the other hand, the origin of the significant difference between the magnitudes of the luminescence modulation in the two samples remains unclear. It might be related to the particular distribution of CdTe nanocrystals within the composites even if the EDX analysis indicates rather random distributions and similar concentrations in both cases. 
It is interesting to compare these curves with data previously published on analogous nanocomposite materials based on $\left[\mathrm{Fe}(\mathrm{H}-\mathrm{trz})_{2}(\operatorname{trz})\right] \mathrm{BF}_{4} @ \mathrm{SiO}_{2}$ core-shell nanoparticles and different luminophores. Titos-Padilla et al. [13,21] functionalized the silica shell with the organic fluorophore 3-(dansylamido)propyltrimethoxysilane exhibiting a broad luminescence emission centered around $490 \mathrm{~nm}$ at room temperature. They observed a marked luminescence intensity drop of $c a .80 \%$ when going from the HS to the LS state, which they attributed to a Förster type energy transfer process. This change was reproducible on the reverse transition, but, for each thermal cycle, an irreversible decrease of $c a$. $20 \%$ of the luminescence occurred as well, which was explained by the thermal decomposition of the luminophore at high temperatures (around $400 \mathrm{~K}$ ). Interestingly, the emission peak maximum shifted also from ca. $490 \mathrm{~nm}$ (LS) to $500 \mathrm{~nm}$ (HS) upon the SCO. In our team we also grafted $\left[\mathrm{Fe}(\mathrm{H} \text {-trz })_{2}(\mathrm{trz})\right] \mathrm{BF}_{4} @ \mathrm{SiO}_{2}$ particles with a pyrene-derivative fluorophore [22]. The fluorescent composites exhibited both pyrene monomer and excimer luminescence, centered around 430 and $605 \mathrm{~nm}$, respectively. When switching the particles from the HS to the LS state the excimer luminescence intensity decreased by $c a$. $25 \%-45 \%$ (depending on the luminophore quantity) and the emission spectra were redshifted by ca. $15 \mathrm{~nm}$, while the monomer emission exhibited negligible spin-state dependence. Variable temperature luminescence lifetime measurements revealed that the strong coupling of the pyrene excimers with the spin-state of the metal complex occurred via a non-radiative mechanism and it was suggested that the coupling was mediated primarily by the mechanical strain accompanying the SCO. Photobleaching of the luminophore was also observed. Alternatively, we also grafted a $\mathrm{Tb}^{3+}$ complex on the $\left[\mathrm{Fe}(\mathrm{H}-\mathrm{trz})_{2}(\operatorname{trz})\right] \mathrm{BF}_{4} @ \mathrm{SiO}_{2}$ particles [24]. We observed a relatively small $(c a .2 \%)$, but very well reproducible decrease of the most intense ${ }^{5} \mathrm{D}_{4} \rightarrow{ }^{7} \mathrm{~F}_{5}$ transition (centered at $545 \mathrm{~nm}$ ) accompanying the HS to LS transition. Since this intensity modulation was not accompanied by any observable change of the luminescence lifetime we proposed a radiative energy transfer mechanism via (partial) reabsorption of the emitted photons by the LS complexes. In each of these examples, the overall temperature dependence of the luminescence exhibits a very similar hysteresis when compared to that observed here for the CdTe composites highlighting thus the excellent versatility of this approach. The relatively weak variation of the luminescence intensity accompanying the SCO in the CdTe composites suggests that probably a radiative energy transfer process occurs between the luminophore and the iron complex.

We were particularly interested in the origin of the instability of the luminescence signal in the $\mathrm{CdTe}-\mathrm{SCO}$ composites and we have thus investigated the concomitant effect of light exposure and temperature changes on the luminophore itself. Figure $3 a$ presents the fluorescence intensity variation as a function of temperature through five thermal cycles between $323 \mathrm{~K}$ and $403 \mathrm{~K}$ for a fresh sample. The fluorescence intensity has dropped by $c a .65 \%$ after the first cycle, which we attribute tentatively to the desolvation effect. For every further cycle, the fluorescence was bleached to a small extent when compared to the preceding cycle. Figure $3 b$ shows a complete thermal cycle of the luminescence signal of our quantum dots between $323 \mathrm{~K}$ and $403 \mathrm{~K}$. Prior to this measurement, the sample was annealed at $403 \mathrm{~K}$. At the end of the cycle, ca. $9 \%$ intensity loss is observed. The reasons of this luminescence bleaching are not clearly understood, although it might be caused by changes on the surface of the crystals. We have also investigated the thermal variation of the CdTe fluorescence lifetime, which is often a more robust property than the luminescence intensity. Variable temperature luminescence lifetime measurements were performed between $298 \mathrm{~K}$ and $373 \mathrm{~K}$ for a complete thermal cycle. Figure 3c shows the three-exponential fit of the raw decay data acquired at $298 \mathrm{~K}$ and $368 \mathrm{~K}$. As expected, an important lifetime decrease is observed at higher temperature due to the thermal activation of non-radiative decay channels. The evolution of the luminescence lifetime as a function of the temperature is also plotted in Figure 3d. As the temperature increases from $298 \mathrm{~K}$ and $373 \mathrm{~K}$, the luminescence lifetime decreases from $c a .7 .1 \mathrm{~ns}$ to $3.1 \mathrm{~ns}$. When the temperature decreases to the initial value, the lifetime recovers only to $c a .5 .7 \mathrm{~ns}$. This thermal instability of the lifetime may be linked to the photothermal degradation of the nanocrystal surface, which can affect the exciton lifetime. The fact that the luminescence decay must be fitted with a multi-exponential function indicates that different 
types of excitons contribute to the overall emission process and it is possible that the photobleaching does not affect them in the same way, leading to a change of the average lifetime as well. Similar to our results, several publications have mentioned the strong decrease of fluorescence intensity and lifetime upon the increase of the temperature (see for example References [33-35]). However, most of these publications have failed to notice the partial irreversibility of these changes over thermal cycles which is clearly seen in our experiments.
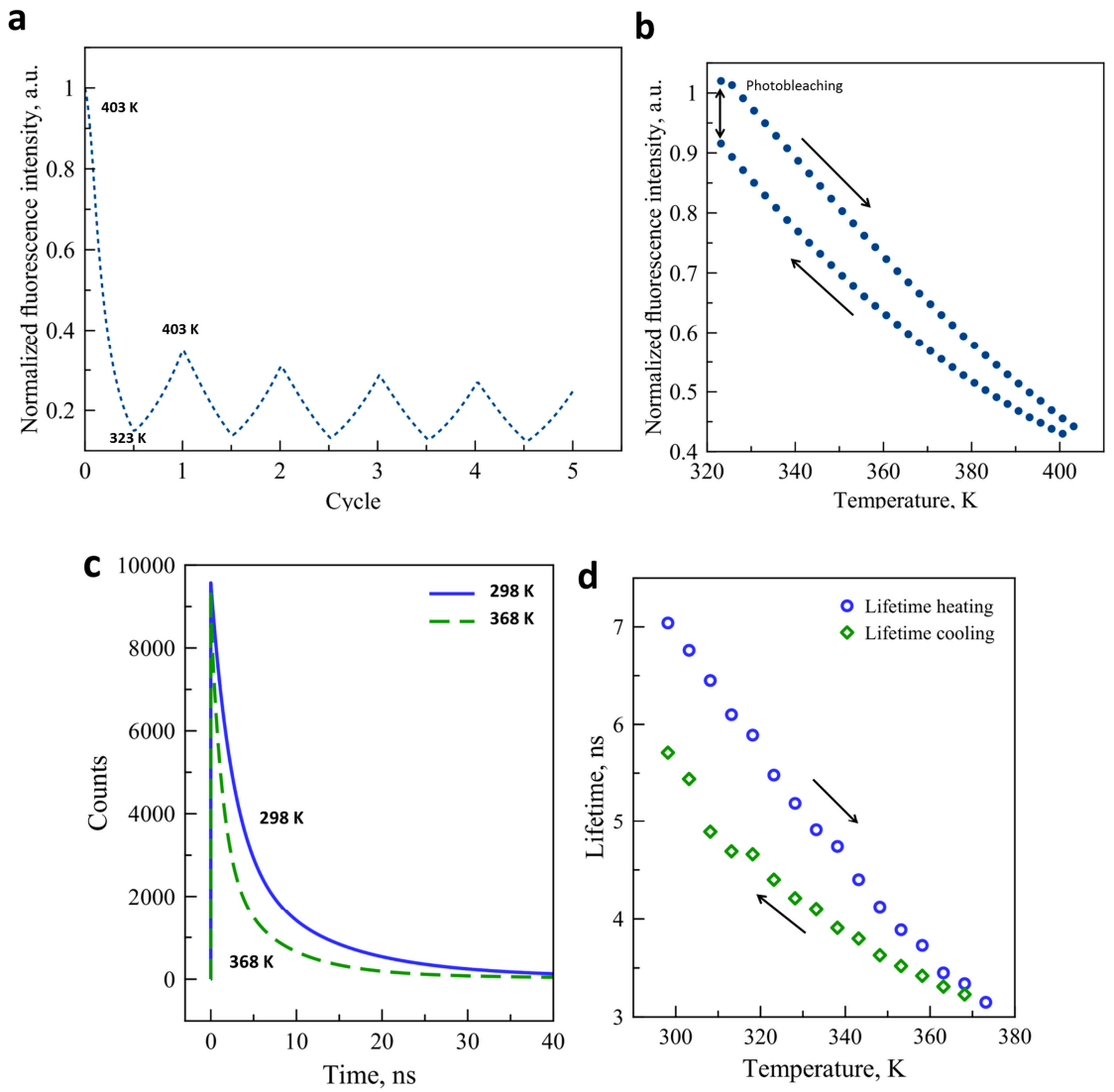

Figure 3. (a) Fluorescence intensity variation of CdTe quantum dots for 5 consecutive temperature cycles $\left(\lambda_{\mathrm{ex}}=450 \mathrm{~nm}, \lambda_{\mathrm{em}}=550 \mathrm{~nm}\right)$; (b) Temperature dependence of the luminescence intensity of CdTe through a complete heating-cooling cycle; (c) Luminescence decay curves of CdTe nanocrystals at $298 \mathrm{~K}$ and $368 \mathrm{~K}\left(\lambda_{\mathrm{ex}}=449 \mathrm{~nm}, \lambda_{\mathrm{em}}=540 \mathrm{~nm}\right)$; (d) Lifetime of CdTe luminescence as a function of temperature on heating and cooling.

\section{Experimental Details}

$\left[\mathrm{Fe}(\mathrm{H}-\mathrm{trz})_{2}(\mathrm{trz}) \mathrm{BF}_{4} @ \mathrm{SiO}_{2}\right.$ core-shell particles were synthesized as reported in Reference [31]. A similar strategy was used to synthesize $\left[\mathrm{Fe}(\mathrm{H}-\operatorname{trz})_{2}(\operatorname{trz})\right] \mathrm{BF}_{4}$ particles without $\mathrm{SiO}_{2}$ shell, modifying also the reactant concentrations (in this case a two-fold molar excess ligand to iron salt was used). In a second step, these particles were covered by a branched polyethylenimine (BPEI) polymer. CdTe nanocrystals, $2 \mathrm{~nm}$ in diameter, coated with $\mathrm{COOH}$ groups, were purchased from Plasmachem (Berlin, Germany) and present luminescence emission centered at $520 \pm 5 \mathrm{~nm}$ in aqueous solution. The SCO@SiO 2 or SCO@BPEI particles $(100 \mathrm{mg})$ were mixed with the fluorescent CdTe nanocrystals $(0.5 \mathrm{mg})$ overnight in $10 \mathrm{~mL}$ ethanol/water (1:1) mixture and the resulting suspension was centrifuged affording samples $\left[\mathrm{Fe}(\mathrm{H}-\mathrm{trz})_{2}(\mathrm{trz}) \mathrm{BF}_{4} @ \mathrm{SiO}_{2} @ \mathrm{CdTe}(\mathbf{1})\right.$ and $\left[\mathrm{Fe}(\mathrm{H}-\operatorname{trz})_{2}(\operatorname{trz}) \mathrm{BF}_{4} @ \mathrm{BPEI} @ \mathrm{CdTe}(\mathbf{2})\right.$. Transmission electron microscopy (TEM) images were obtained by using a JEOL JEM 1011 electron microscope (JEOL, Dearborn, MA, USA) operated at 100 kV. High resolution Transmission Electronic Microscopy (HRTEM) coupled energy-dispersive X-ray spectroscopy (EDX) analysis were carried out 
using high-resolution microscope JEOL JSM 2100F (JEOL, Dearborn, MA, USA) operated at $200 \mathrm{kV}$. Fluorescence microscopy images have been recorded with an Olympus BX51 upright microscope (Olympus, Tokyo, Japan) equipped with a $100 \mathrm{~W}$ halogen lamp, a CCD image sensor (Clara, Andor Technology, Belfast, UK) and $\mathrm{a} \times 5(\mathrm{NA}=0.1)$ or $\mathrm{a} \times 50(\mathrm{NA}=0.5)$ magnification objective. The excitation and collected light beams were separated by a dichroic mirror with a cutting edge at $510 \mathrm{~nm}$ and band-pass filters centered at $450 \mathrm{~nm}(\mathrm{FWHM}=45 \mathrm{~nm})$ and at $550 \mathrm{~nm}(\mathrm{FWHM}=50 \mathrm{~nm})$ for excitation and emission, respectively. For spectroscopic analysis we used a Shamrock SR-303i imaging spectrometer (Andor Technology, Belfast, UK), which was connected to the microscope by an optical fiber. Luminescence lifetime measurements were performed using the time-correlated single photon counting (TCSPC) technique by means of a DeltaFlex (Horiba, Kyoto, Japan) instrument equipped with a $449 \mathrm{~nm}$ electroluminescent diode (pulse duration $1.2 \mathrm{~ns}$ ). Detection was performed by setting the emission monochromator to $540 \mathrm{~nm}$ completed with an additional bandpass filter around this wavelength. Fittings and lifetime calculations were performed using the DAS6 fluorescence decay analysis software (Horiba, Kyoto, Japan). Variable temperature experiments were carried out in ambient air at a rate of $5 \mathrm{Kmin}^{-1}$ using a Linkam THMS600 cryostat (Linkam Scientific Instruments, Tadworth, UK).

\section{Conclusions}

We synthesized nanocomposite materials based on luminescent CdTe nanocrystals and $\left[\mathrm{Fe}(\mathrm{H}-\mathrm{trz})_{2}(\mathrm{trz}) \mathrm{BF}_{4}\right.$ nanoparticles enrobed either with $\mathrm{SiO}_{2}$ or BPEI shells. Both samples exhibited a reversible modulation of the luminescence intensity upon the spin transition. Owing to the rather week luminescence modulation we tentatively attributed this phenomenon to a radiative energy transfer mechanism between the luminophore and the spin crossover complex resulting from the spectral overlap between the luminescence emission and the absorption of the complex in the LS state. The photo-thermal degradation of the luminophore was also observed and further work should focus on solving this issue by appropriate surface modification (encapsulation) of the CdTe nanocrystals [36]. The most interesting perspective of the present work will be the detailed investigation of the relationship between the spectral overlap and the luminescence modulation. To this aim CdTe nanocrystals provide an excellent scope as their emission spectra can be tuned over a wide spectral range ( $c a .500-800 \mathrm{~nm}$ ) around the metal-centered absorption bands of our SCO complex. As a more general conclusion, it appears that by an appropriate choice of the spectral characteristics of the luminophore its emission will be inexorably modulated by the SCO phenomenon in this type of hybrid nanocomposites. The nature of the luminophore used and the way it is mixed with the SCO entities will determine 'merely' the magnitude of the luminescence modulation. This allows one to change the luminescent properties of the composite material (for example, the $\mathrm{Tb}^{3+}$ emission is characterized by sharp lines and long decays, while pyrene and CdTe exhibit broad emission bands and fast decays), while keeping virtually the same spin crossover properties.

Acknowledgments: This work was performed in the frame of the International Associated Laboratory (LIA) Kiev-Toulouse. We thank the Agence National de la Recherche (project ANR-13-BS07-0020-01) and the French Embassy in Ukraine for financial support.

Author Contributions: L.S., G.M and A.B. conceived and designed the experiments; O.K. and I.S. performed the experiments; O.K. and I.S. analyzed the data; L.S. and G.M. contributed reagents/materials/analysis tools; L.S., G.M. and A.B. wrote the paper.

Conflicts of Interest: The authors declare no conflict of interest.

\section{References}

1. Bousseksou, A.; Molnar, G.; Salmon, L.; Nicolazzi, W. Molecular spin crossover phenomenon: Resent achievements and prospects. Chem. Soc. Rev. 2011, 40, 3313-3335. [CrossRef] [PubMed]

2. Shepherd, J.; Quintero, C.M.; Molnar, G.; Salmon, L.; Bousseksou, A. Spin-Crossover Materials; Halcrow, M.A., Ed.; John Wiley \& Sons Ltd.: Oxford, UK, 2013; pp. 347-373. 
3. Piguet, C.; Rivara-Minten, E.; Hopfgartner, G.; Bünzli, J.-C.G. Molecular magnetism and iron(II) spin-state equilibrium as structural probes in heterodinuclear d-f complxes. Helv. Chim. Acta 1995, 78, 1651-1672. [CrossRef]

4. Piguet, C.; Rivara-Minten, E.; Bernardinelli, G.; Bünzli, J.-C.G.; Hopfgartner, G. Non-covalent lanthanide podates with predetermined physicochemical properties: Iron(II) spin-state equilibria in self-assembled heterodinuclear d-f supramolecular complexes. J. Chem. Soc. Dalton Trans. 1997, 421-434. [CrossRef]

5. Engeser, M.; Fabbrizzi, L.; Licchelli, M.; Sacchi, D. A fluorescent molecular thermometer based on the nickel(II) high-spin/low-spin interconversion. Chem. Commun. 1999, 1191-1192. [CrossRef]

6. Edder, C.; Piguet, C.; Bünzli, J.-G.; Hopfgartner, G. High-spin iron(II) as a semitransparent partner for tuning europium(III) luminescence in heterodimetallic d-f complexes. Chem. Eur. J. 2001, 7, 3014-3024. [CrossRef]

7. Hasegawa, M.; Renz, F.; Hara, T.; Kikuchi, Y.; Fukuda, Y.; Okubo, J.; Hoshi, T.; Linert, W. Fluorescence spectra of Fe(II) spin crossover complexes with 2,6-bis(benzimidazole-2' -yl)pyridine. Chem. Phys. 2002, 277, 21-30. [CrossRef]

8. Matsuda, M.; Isozaki, H.; Tajima, H. Electroluminescence quenching caused by a spin-crossover transition. Chem. Lett. 2008, 374-375. [CrossRef]

9. Matsuda, M.; Isozaki, H.; Tajima, H. Reproducible on-off switching of the light emission from the electroluminescent device containing a spin crossover complex. Thin Solid Films 2008, 517, 1465-1467. [CrossRef]

10. Matsukizono, H.; Kuroiwa, K.; Kimizuka, N. Self-assembly-directed spin conversion of iron(II) 1,2,4-triazole complexes in solution and their effect on photorelaxation processes of fluorescent counter ions. Chem. Lett. 2008, 446-447. [CrossRef]

11. Tovee, C.A.; Kilner, C.A.; Thomas, J.A.; Halcrow, M.A. Co-crystallising two functional complex molecules in a terpyridine embrace lattice. Cryst. Eng. Commun. 2009, 11, 2069-2077. [CrossRef]

12. Salmon, L.; Molna'r, G.; Zitouni, D.; Quintero, C.; Bergaud, C.; Micheau, J.-C.; Bousseksou, A. A novel approach for fluorescent thermometry and thermal imaging purposes using spin crossover nanoparticles. J. Mater. Chem. 2010, 20, 5499-5503. [CrossRef]

13. Titos-Padilla, S.; Herrera, J.M.; Chen, X.-W.; Delgado, J.J.; Colacio, E. Bifunctional hybrid $\mathrm{SiO}_{2}$ nanoparticles showing synergy between core spin crossover and shell luminescence properties. Angew. Chem. Int. Ed. 2011, 50, 3290-3293. [CrossRef] [PubMed]

14. Garcia, Y.; Robert, F.; Naik, A.D.; Zhou, G.; Tinant, B.; Robeyns, K.; Michotte, S.; Piraux, L. Spin transition charted in a fluorophore-tagged thermochromic dinuclear iron(II) complex. J. Am. Chem. Soc. 2011, 133, 15850-15853. [CrossRef] [PubMed]

15. Gonzalez-Prieto, R.; Fleury, B.; Schramm, F.; Zoppellaro, G.; Chandrasekar, R.; Fuhr, O.; Lebedkin, S.; Kappes, M.; Ruben, M. Tuning the spin-transition properties of pyrene-decorated 2,6-bispyrazolylpyridine based Fe(II) complexes. Dalton Trans. 2011, 40, 7564-7570. [CrossRef] [PubMed]

16. Quintero, C.M.; Gural'skiy, I.A.; Salmon, L.; Molnar, G.; Bergaud, C.; Bousseksou, A. Soft lithographic patterning of spin crossover complexes. Part 1: Fluorescent detection of the spin transition in single nano-objects. J. Mater. Chem. 2012, 22, 3745-3751. [CrossRef]

17. Gural'skiy, I.A.; Quintero, C.M.; Abdul-Kader, K.; Lopes, M.; Bartual-Murgui, C.; Salmon, L.; Zhao, P.; Molnar, G.; Astruc, D.; Bousseksou, A. Detection of molecular spin-state changes in ultrathin films by photonic methods. J. Nanophotonics 2012, 6. [CrossRef]

18. Matsuda, M.; Kiyoshima, K.; Uchida, R.; Kinoshita, N.; Tajima, H. Characteristics of organic light-emitting devices consisting of dye-doped spin crossover complex films. Thin Solid Films 2013, 531, 451-453. [CrossRef]

19. Nagy, V.; Halász, K.; Gural'skiy, I.A.; Tricard, S.; Carayon, M.-T.; Molnár, G.; Bousseksou, A.; Salmon, L.; Csóka, L. Cellulose fiber nanocomposites displaying spin-crossover properties. Colloids Surf. A 2014, 456, 35-40. [CrossRef]

20. Santoro, L.J.; Cook, R.K.; Kulmaczewski, S.A.; Barrett, O.; Halcrow, M.A. Iron(II) complexes of tridentate indazolylpyridine ligands: Enhanced Spin-crossover hysteresis and ligand-based fluorescence. Inorg. Chem. 2015, 54, 682-693. [CrossRef] [PubMed]

21. Herrera, J.M.; Titos-Padilla, S.; Pope, S.; Berlanga, I.; Zamora, F.; Delgado, J.J.; Kamenev, K.; Wang, X.; Prescimone, A.; Brechin, E.K.; et al. Studies on bifunctional Fe(II)-triazole spin crossover nanoparticles: Time-dependent luminescence, surface grafting and the effect of a silica shell and hydrostatic pressure on the magnetic properties. J. Mater. Chem. C 2015, 3, 7819-7829. [CrossRef] 
22. Suleimanov, I.; Kraieva, O.; Costa, J.S.; Fritsky, I.O.; Molnár, G.; Salmon, L.; Bousseksou, A. Electronic communication between fluorescent pyrene excimers and spin crossover complexes in nanocomposite particles. J. Mater. Chem. C 2015, 3, 5026-5032. [CrossRef]

23. Nagy, V.; Suleimanov, I.; Molnár, G.; Salmon, L.; Bousseksou, A.; Csóka, L. Cellulose-spin crossover particle composite papers with reverse printing performance: A proof of concept. J. Mater. Chem. C 2015, 3, 7897-7905. [CrossRef]

24. Suleimanov, I.; Kraieva, O.; Molnár, G.; Salmon, L.; Bousseksou, A. Enhanced luminescence stability with a Tb-spin crossover nanocomposite for spin state monitoring. Chem. Commun. 2015, 51, 15098-15101. [CrossRef] [PubMed]

25. Wang, C.-F.; Li, R.-F.; Chen, X.-Y.; Wei, R.-J.; Zheng, L.-S.; Tao, J. Synergetic spin crossover and fluorescence in one-dimensional hybrid complexes. Angew. Chem. Int. Ed. 2015, 54, 1574-1577. [CrossRef] [PubMed]

26. Lochenie, C.; Wagner, K.G.; Karg, M.; Weber, B. Modulation of the ligand-based fluorescence of 3D metal complexes upon spin state change. J. Mater. Chem. C 2015, 3, 7925-7935. [CrossRef]

27. Cook, L.J.K.; Halcrow, M.A. Doping ruthenium complexes into a molecular spin-crossover material. Polyhedron 2015, 87, 91-97. [CrossRef]

28. Kumar, K.S.; Salitros, I.; Heinrich, B.; Fuhr, O.; Ruben, M. A charge neutral iron(II) complex with an above room temperature spin crossover (SCO) and hysteresis loop. J. Mat. Chem. C 2015, 3, 11635-11644. [CrossRef]

29. Weller, H. Quantum size colloids: From size-dependent properties of discrete particles to self-organized superstructures. Curr. Opin. Colloid Interface Sci. 1998, 3, 194-199. [CrossRef]

30. Alivisatos, A.P. Semiconductor clusters, nanocrystals, and quantum dots. Science 1996, 271, $933-937$. [CrossRef]

31. Suleimanov, I.; Costa, J.S.; Molnar, G.; Salmon, L.; Bousseksou, A. The photo-thermal plasmonic effect in spin crossover@silica-Gold nanocomposites. Chem. Commun. 2014, 50, 13015-13018. [CrossRef] [PubMed]

32. Tissot, A.; Enachescu, C.; Boillot, M.-L. Control of the thermal hysteresis of the prototypal spin-transition $\mathrm{Fe}^{\mathrm{II}}$ (phen) $)_{2}(\mathrm{NCS})_{2}$ compound via the microcrystallites environment: Experiments and mechanoelastic model. J. Mater. Chem. 2012, 22, 20451-20457. [CrossRef]

33. Walker, G.W.; Sundar, V.C.; Rudzinski, C.M.; Wun, A.W.; Bawendi, M.G.; Nocera, D.G. Quantum-dot optical temperature probes. Appl. Phys. Lett. 2003, 83, 3555-3557. [CrossRef]

34. Liu, W.; Zhang, Y.; Zhai, W.; Wang, Y.; Zhang, T.; Gu, P.; Chu, H.; Zhang, H.; Cui, T.; Wang, Y.; et al. Temperature-dependent photoluminescence of ZnCuInS/ZnSe/ZnS quantum dots. J. Phys. Chem. C 2013, 117, 19288-19294. [CrossRef]

35. Wang, S.; Westcott, S.; Chen, W. Nanoparticle Luminescence Thermometry. J. Phys. Chem. B 2002, 106, 11203-11209. [CrossRef]

36. Cai, E.; Ge, P.; Lee, S.H.; Jeyifous, O.; Wang, Y.; Liu, Y.; Wilson, K.M.; Lim, S.J.; Baird, M.A.; Stone, J.E.; et al . Stable small quantum dots for synaptic receptor tracking on live neurons. Angew. Chem. Int. Ed. 2014, 53, 12484-12488.

(C) 2016 by the authors; licensee MDPI, Basel, Switzerland. This article is an open access article distributed under the terms and conditions of the Creative Commons by Attribution (CC-BY) license (http://creativecommons.org/licenses/by/4.0/). 